\title{
PEMBELAJARAN FISIKA MENGGUNAKAN PENDEKATAN KETERAMPILAN PROSES PADA KONSEP USAHA BAGI SISWA SMP
}

\author{
Aprilia Londonaung, Tineke Rondonuwu \\ Fakultas Matematika dan Ilmu Pengetahuan Alam, Universitas Negeri Manado \\ email: aprilia07@gmail.com
}

\begin{abstract}
ABSTRAK
Pendekatan keterampilan proses adalah suatu pendekatan yang sesuai dengan karakter Ilmu Pengetahuan Alam (IPA) khususnya Fisika pada pokok bahasan Usaha. Penelitian ini bertujuan untuk meningkatkan pemahaman konsep fisika dengan menggunakan keterampilan proses pada siswa SMP kelas VIII. Penelitian ini adalah penelitian Tindakan kelas (PTK) yang menurut Muhammad Afandi, PTK atau CAR (Classroom Action Research) digunakan untuk mengatasi masalah yang muncul di dalam kelas. Pelaksanaan penelitian mengikuti tahapan perencanaan, pelaksanaan tindakan, pengamatan, refleksi dan berulang kembali setelah hasil refleksi merekomendasikan untuk lanjut ke siklus II. Hasil penelitian menunjukkan bahwa setelah siklus I ada $40 \%$ siswa yang belum tuntas belajar, dan setelah dilanjutkan dengan siklus II, terdapat 2 orang siswa $(6,66 \%)$ yang tidak tuntas belajar atau 93,34\% siswa tuntas belajar. Karena itu penelitian ini menyimpulkan bahwa penggunaan pendekatan proses pada konsep usaha di kelas VIII SMP dapat meningkatkan hasil belajar siswa.
\end{abstract}

Kata kunci : pendekatan proses, usaha

\begin{abstract}
The skills approach is an approach that is in accordance with the character of Natural Sciences (IPA), especially Physics on the subject of Business. This study aims to improve understanding of the concept of physics by using the process in class VIII junior high school students. This research is a classroom action research (CAR) which according to Muhammad Afandi, PTK or CAR (Classroom Action Research) is used to solve problems that arise in class. Implementation follows the stages of planning, implementing actions, observing, reflecting and repeating after reflection on recommendations to continue to cycle II. The results showed that after the first cycle there were $40 \%$ of students who had not finished studying, and after continuing with the second cycle, there were 2 students $(6.66 \%)$ who did not complete their studies or $93.34 \%$ of the students finished learning. Therefore, it is concluded that the use of the business concept approach in class VIII SMP can improve student learning outcomes.
\end{abstract}

Keywords : process approach, work 


\section{PENDAHULUAN}

Situasi belajar harus dirancang sedemikian rupa untuk mengaktifkan, mendukung dan mempertahankan proses internal yang terdapat dalam setiap belajar.

Untuk menunjang proses belajar mengajar orang mengembangkan berbagai pengetahuan, misalnya psikologi pendidikan, metode pengajaran, pengelolaan pengajaran, dan ilmuilmu lain. Salah satu faktor yang menentukan hasil belajar adalah pendekatan pengajaran yang digunakan guru dalam proses belajar mengajar untuk mencapai tujuan pengajaran sehingga mempengaruhi perilaku siswa (Kustandi, 2015).

Pembelajaran merupakan usaha sadar dan disengaja oleh guru untuk membuat siswa belajar dengan jalan mengaktifkan faktor internal dan faktor eksternal dalam kegiatan belajarnya. Dalam proses belajar mengajar, guru menyampaikan suatu materi pelajaran yang disesuaikan dengan tujuan pengajaran, sementara peserta didik berkewajiban mempelajari materi pelajaran tersebut dengan maksud agar terjadi transfer pengetahuan. Untuk menunjang proses belajar mengajar orang mengembangkan berbagai pengetahuan, misalnya psikologi pendidikan, metode pengajaran, pengelolaan pengajaran, dan ilmuilmu lain. Salah satu faktor yang menentukan hasil belajar adalah pendekatan pengajaran yang digunakan guru dalam proses belajar mengajar untuk mencapai tujuan pengajaran sehingga mempengaruhi perilaku siswa.

Pada saat ini berbagai masalah dalam bidang pendidikan menuntut upaya pemikiran bersama, salah satu diantaranya adalah masalah yang berkaitan dengan pengajaran bidang studi IPA Fisika, siswa hanya memahami apa yang diajarkan guru dan guru mengajar tidak sesuai bidangnya. Sehingga pemahaman dan rasa ingin tahu siswa mengenai konsep masih relatif rendah, angka terendah yang dicapai oleh siswa adalah 55 sedangkan KKM IPA Fisika adalah 75. Oleh karena itu siswa perlu dilatih kritis dan bertindak kreatif.

Guru wajib memiliki kualifikasi akademik, kompetensi, sertifikat pendidik, sehat jasmani dan rohani, serta memiliki kemampuan untuk mewujudkan tujuan pendidik nasional. Dalam ayat 1 lebih dijelaskan mengenai kompetensi yang dimaksud yaitu meliputi kompetensi pedagogik, kompetensi kepribadian, kompetensi sosial, dan kompetensi profesioanal yang diperoleh melalui pendidikan profesi.

Menyelesaikan masalah pembelajaran yang berkaitan dengan kualitas pembelajaran tersebut, perlu diterapkannya proses pembelajan inovatif untuk meningkatkan kualitas pembelajaran IPA Fisika di kelas VIII SMP yaitu Pembelajaran Fisika Menggunakan Pendekatan Keterampilan.

Pendekatan keterampilan proses adalah suatu pendekatan yang sesuai dengan karakter IPA khususnya Fisika pada pokok bahasan Usaha. Keterampilan proses mempunyai komponen mengamati (observasi), menggolongkan (klasifikasi), menafsirkan (menginterpretasi), meramalkan (memprediksi), menerapkan, merencanakan penelitian, dan mengkomunikasikan. Pendekatan keterampilan proses mensyaratkan keaktifan siswa dalam pembeljaran dan siswa diharapkan mampu menemukan konsep yang dipelajari secara mandiri (Lumbu,A dkk.2018).

Secara konseptual belajar keterampilan proses mempunyai ciri sebagai berikut; (1). Menekankan pentingnya keberartian belajar untuk mencapai hasil belajar yang memadai, (2). Menekankan pentingnya keterlibatan siswa dalam proses belajar, (3). Menekankan bahwa belajar adalah proses dua arah (4). Menekankan hasil belajar secara tuntas (Rusyan A, Tabrani, dkk, 1989).

Pembelajaran Fisika dengan menggunakan pendekatan keterampilan proses melalui metode eksperimen akan memberikan pengaruh terhadap siswa dalam upaya mempelajari dan memahami konsep-konsep Fisika pada pokok bahasan usaha. Salah satu parameter keberhasilan dalam belajar mengajar adalah keberhasilan siswa dalam memahami konsep Fisika. Pemahaman konsep dapat dilihat dari aspek kognitif, afektif dan psikomotorik. Pada penelitian ini, penulis akan melihat pemahaman konsep Fisika siswa dari aspek kognitif, yaitu terkait dengan pengetahuan, pemahaman, penerapan dan analisis. Dimana hal tersebut dapat diwujudkan dalam tes prestasi.

\section{METODE PENELITIAN}

Penelitian ini dilakukan di kelas VIII SMP Negeri 5 Tabukan Utara dengan jumlah siswa 30 orang yang terdiri dari 10 laki-laki dan 20 
perempuan. Penelitian ini dilaksanakan pada semester genap tahun ajaran 2019/2020 pada bulan September sampai bulan November

Penelitian tentang pembelajaran fisika menggunakan pendekatan keterampilan proses pada konsep usaha bagi siswa SMP.

Penelitian ini dilaksanakan dalam bentuk Penelitian Tindakan Kelas (PTK). Menurut Muhammad Afandi, PTK atau CAR (Classroom Action Research) digunakan untuk mengatasi masalah yang muncul di dalam kelas. Banyak model yang dapat digunakan sebagai pedoman dalam merancang dan melaksanakan penelitian tindakan kelas sesuai dengan permasalahan yang muncul di dalam kelas. Dalam penelitian ini digunakan PTK model John Elliot. Model ini menekankan pada proses untuk mencoba hal-hal baru dalam pembelajaran. PTK Model John Elliot terdiri dari beberapa siklus yaitu siklus 1 dan siklus 2 . Dalam setiap siklus terdapat beberapa langkah, yakni perencanaan, pelaksanaan, pengamatan, dan refleksi yang berlaku untuk setiap siklus. Adanya langkah-langkah untuk setiap tindakan ini dengan dasar pemikiran bahwa di dalam suatu mata pelajaran terdiri dari beberapa materi yang tidak dapat diselesaikan dalam satu kali tindakan. Oleh karena itu untuk menyelesaikan suatu pokok bahasan tertentu diperlukan beberapa kali langkah tindakan dalam suatu kegiatan belajar mengajar.

\section{HASIL DAN PEMBAHASAN}

Belajar dilakukan untuk mengusahakan adanya perubahan perilaku pada individu yang belajar. Aspek perubahan itu mengacu kepada taksonomi tujuan pengajaran yang dikembangkan oleh Bloom, Simpson, dan Harrow mencakup aspek kognitif, afektif dan psikomotorik.

Berdasarkan penjelasan diatas dapat kita simpulkan bahwa hasil belajar adalah kemampuan-kemampuan yang dimiliki siswa setelah menerima pengalaman belajarnya.

Penelitian ini dilaksanakan dalam 2 siklus pada semester genap kelas VIII SMP Negeri 5 Tabukan Utara dengan jumlah siswa 30 orang yang terdiri dari 10 laki-laki dan 20 perempuan. Penelitian ini dilaksanakan pada semester genap yang dipusatkan pada mata pelajaran Fisika dengan menggunakan model pembelajaran Konsep Usaha.

Dalam penelitian ini data yang diambil adalah hasil belajar siswa pada mata pelajaran usaha.

Data hasil pretest dan hasil siklus I dapat dilihat pada Gambar 1

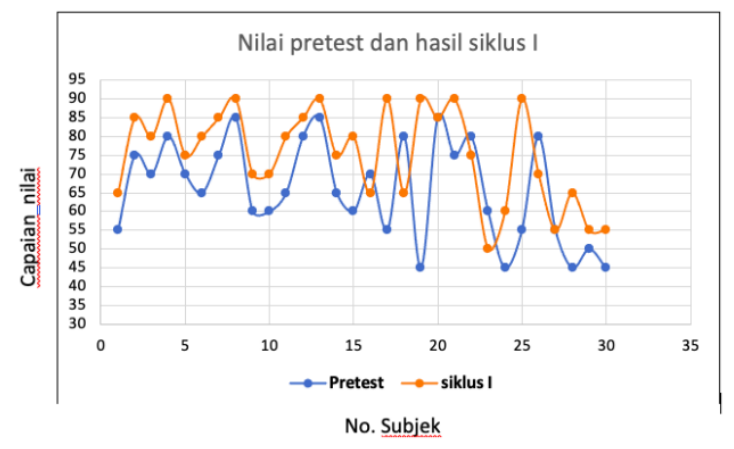

Gambar 1. Grafik nilai capaian siklus I

Gambar 1 menginformasikan variasi nilai yang dicapai masing masing siswa menurut kemampuan masing masing. Nampak bahwa nilai yang diperoleh siswa setelah ada tindakan pada sikls I lebih baik dari nilai pretest.

Tabel 1. berikut ditampilkan data statistik hasil pembelajaran di siklus I

Tabel 1. Data statistik siklus I

\begin{tabular}{cc}
\hline Jumlah data & 30 \\
\hline Nilai minimum & 50 \\
\hline Nilai maksimum & 90 \\
\hline Rata tata & 75,33 \\
\hline Standar Dev & 12,59 \\
\hline Varians & 158,51 \\
\hline$\%$ ketuntasan & 60 \\
\hline
\end{tabular}

Data pada tabel 1 menunjukkan nilai rata rata sudah berada di atas nilai $\mathrm{KKM} \geq 75$, dan $\%$ ketuntasan di atas $50 \%$.

Hasil refleksi menunjukkan bahwa dari 30 siswa subjek penelitian masih terdapat 12 orang siswa yang belum tuntas atau belum mencapai KKM. Masih perlu perbaikan pada proses pembelajaran terutama untuck mendorong keseriusan siswa dalam belajar, dalam berdiskusi dan melakukan pengamatan dan pengukuran. Karena itu perlu ada Tindakan lanjutan. Pada siklus selanjutnya guru harus lebih aktif lagi untuk mengalihkan perhatian siswa agar lebih fokus untuk belajar. Pada pelaksanaan siklus II ini, materi pelajaran yang akan diberikan adalah lanjutan dari materi sebelumnya yaitu tahap-tahap membuat dan menggunakan Contoh usaha di kehidupan 
sehari-hari. Selanjutnya guru menjelaskan dengan baik dan benar materi pembelajaran yang ada, guru memanfaatkan lingkungan sekolah untuk membantu siswa dalam kegiatan belajar mengajar untuk mencapai tujuan pembelajaran yang sesuai dengan standar keberhasilan. Dalam tahap ini, siswa mulai mengerti dengan model pembelajaran yang diterapkan. Proses belajar mengajar sudah lebih kondusif sehingga hasil belajar meningkat dibandingkan dengan hasil belajar di siklus I. Data hasil belajar siswa disiklus II setelah mendapat perlakuan dapat dilihat pada gambar 2 di bawah ini:

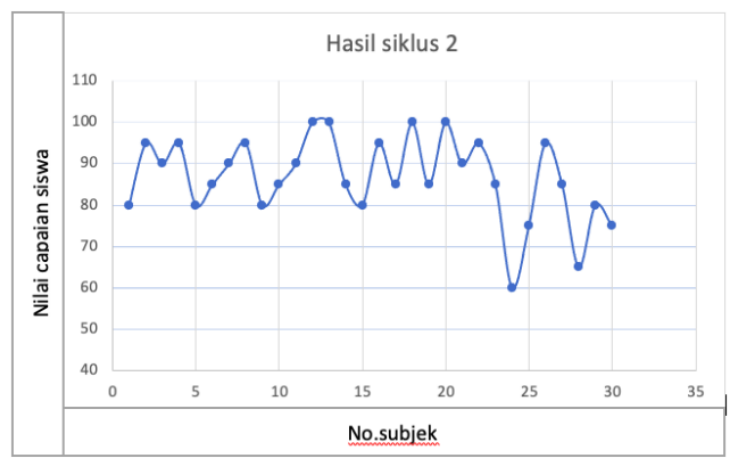

Gambar 2. Grafik capaian belajar siswa hasil evaluasi postest

Gambar 2 menginformasikan bahwa hasil test kegiatan siklus 2 terdapat 4 siswa yang mendapat nilai 100 dan ada 1 siswa mendapat nilai terendah 60 dan sebagian besar siswa mendapat nilai antara 80 -90. Capaian belajar siswa di siklus 2 cukup baik.

Tabel 2 Data staistik siklus II

\begin{tabular}{|c|c|}
\hline jumlah data & 30 \\
\hline Nilai minimum & 60 \\
\hline Nilai maksimum & 100 \\
\hline Rata tata & 86,67 \\
\hline stdv & 9,94 \\
\hline Var.s & 98,85 \\
\hline \% Ketuntasan & 96,67 \\
\hline
\end{tabular}

Tabel 2 menunjukkan bahwa terdapat 96,6 \% siswa sudah tuntas belajar dan nilai varians mengindikasikan diskusi kelompok siswa berjalan baik.

Gambar 3 berikut menampilkan bagan keterlibatan siswa dalam proses belajar mengajar di siklus I dan siklus II.

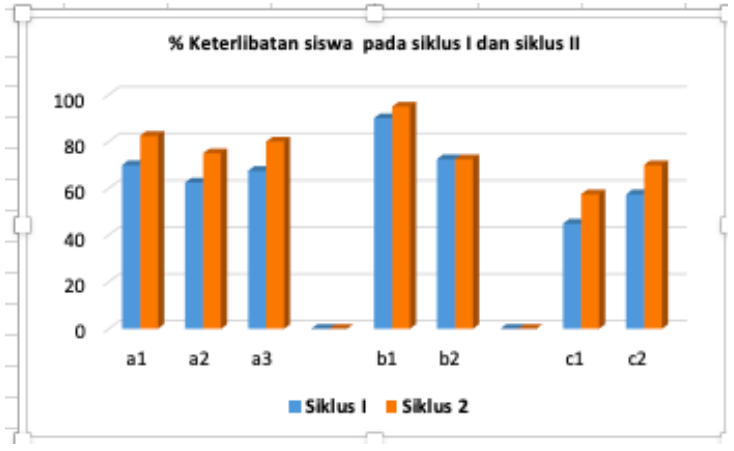

Gambar 3. Bagan keterlibatan siswa dalam proses pembelajaran.

Aktivitas belajar yang direspons baik adalah aktivitas mendengarkan penjelasan dengan saksama, sementara aktivitas mengajukan pertanyaan yang relevan mendapat nilai kurang baik di siklus I maupun disiklus II.

Wahyuni S.dkk.2017. menjelaskan bahwa keterampilan proses memberi kontribusi positif dalam peningkatan kualitas pembelajaan. Lebih lanjut Ango, Mary L.2012 menulis bahwa kenyataan dilapanan pengajaran sains di sekolah dasar dan menengah terlalu sering menekankan pembelajaran hafalan tanpa makna dan tanpa koneksi yang memadai yang dibuat oleh siswa dengan kehidupan sehari-hari mereka. Siswa sering kali keluar dari kelas sains dengan seperangkat definisi yang dihafal, tetapi tanpa sikap ilmiah, tanpa keahlian yang cukup dalam keterampilan proses ilmiah dan tanpa kemampuan substansial untuk menghubungkan konsep ilmiah dengan kehidupan sehari-hari mereka. Karena itu perlu pendekatan proses sains dalam pembelajaran. Data pada tabel 1 dan pada tabel 2 . Mengindikasikan bahwa ada peningkatan pemahaman siswa terhadap konsep usaha. Pada siklus I ada $60 \%$ dari jumlah siswa yang tuntas belajar, sedangkan pada siklus II jumlah sisiwa yang tuntas beajar menjadi 96,6 \% tuntas belajar. Demikian halnya aktivitasbelajar siswa meningkat sebagaimana yang ditunjukkan data pada gambar 3. Karena itu penelitian ini dapat disimpulkan bahwa

Penerapan pendekatan pembelajaran menggunakan keterampilan proses dapat meningkatkan pemahaman konsep usaha pada siswa SMP kelas VIII

\section{KESIMPULAN}

Hasil penelitian menunjukkan bahwa setelah siklus I ada $40 \%$ siswa yang belum 
tuntas belajar, dan setelah dilanjutkan dengan siklus II, terdapat 2 orang siswa ( $6,66 \%$ ) yang tidak tuntas belajar. Penerapan pendekatan pembelajaran menggunakan ketrampilan proses dapat meningkatkan pemahaman konsep usaha pada siswa SMP kelas VIII Semester II.

\section{REFERENSI}

Ango, Mary L.2012. Mastery of Science Process Skills and Their Effective Use in the Teaching of Science: An Educology of Science Education in the Nigerian Context

Online Submission, International Journal of Educology v16 n1 p11-30 2002

Aqib Zainal dkk. (2008). Penelitian Tindakan Kelas. Bandung: CV.YramaWidyaa

Bob Foster..2004. Sains Fisika SMP Kelas VIII. Jakarta : Erlangga.

Budiningsih A,(2005)..Belajar dan pembelajaran.Jakarta:Rineke Cipta Ilmu

Cecep Kustandi, 2015. Pengertian pembelajaran

Lumbu A, Walukow A, Panda F.M. 2018. Deskripsi keterampilan guru fisika SMA Negeri 1 Jayapura dalam menerapkan pendekatan keterampilan proses sains di kelas XI IPA Jurnal Pembelajaran Sains Volume 2 Nomor 2.

Mulysa E.2005.Menjadi Guru Profesional.Bandung : Remaja Rosdakarya.

Nur Hidayah. (2013). Panduan Praktis Penyusunan Dan Pelaporan Penelitian Tindakan Kelas (PTK). Jakarta: PT Prestasi Pustakaraya

Rini Budiharti.1990.Strategi Belajar Mengajar Bidang Studi.Surakarta : UNS Press

Rusyan A, Tabrani, dkk, 1989, Pendekatan Dalam Proses Belajar Mengajar, Bandung: Remadja Karya

Turang,1980.Kompetensi.Bandung : $\quad$ PT Remaja Rosdakarya

Winarto Surakamad.1990.Indikator Kerampilan Proses Sains.Bandung : Tarsito

Wahyuni S, I. Indrawati, S. Sudarti, W. Suana 2017. Developing Science Process Skills and Problem Solving Abilities Based on Outdoor Learning in Junior High School. Indonesian Journal of Science Education Vol.6 no.1 